\title{
Seasonal Variations of Mid-Latitude lonospheric Trough Structure Observed with DEMETER and COSMIC
}

\author{
Barbara MATYJASIAK, Dorota PRZEPIÓRKA, and Hanna ROTHKAEHL \\ Space Research Centre of Polish Academy of Sciences, Warsaw, Poland, \\ e-mail: bmatyjasiak@cbk.waw.pl
}

\begin{abstract}
The mid-latitude ionospheric trough is a depleted region of ionospheric plasma observed in the topside ionosphere. Its behavior can provide useful information about the magnetospheric dynamics, since its existence is sensitive to magnetospherically induced motions. Midlatitude trough is mainly a night-time phenomenon. Both, its general features and detailed characteristics strongly depend on the level of geomagnetic disturbances, time of the day, season, and the solar cycle, among others. Although many studies provide basic information about general characteristics of the main ionospheric trough structure, an accurate prediction of the trough behavior in specific events is still understood poorly. The paper presents the mid-latitude trough characteristics with regard to the geomagnetic longitude and season during a solar activity minimum, as based on the DEMETER in situ satellite measurements and the data retrieved from FORMOSAT-3/COSMIC radio occultation measurements.
\end{abstract}

Key words: main ionospheric trough, ionosphere, electron density, DEMETER, FORMOSAT-3/COSMIC. 


\section{INTRODUCTION}

The main ionospheric trough (MIT) is a typical feature observed in the subauroral ionospheric region which has been studied for many years (Muldrew 1965, Spiro 1987, Karpatchev 2003, He et al. 2011, Zaalova et al. 2013). The MIT strongly affects the propagation of different natural and artificial signals, thus itis important for radio communication as well as communication and space industry in general (Clilverd et al. 1995).

The trough structure is most developed for altitudes of the F2 layer maximum where significant depletion in electron concentration occurs (during a whole year). The structure seems to exist in the areas where the stagnation of ionospheric plasma takes place, between a region of eastward (corotating) plasma drift and a region of westward drift in the auroral zone (Mallis and Essex 1993, Whalen 1989, Aladjev et al. 2001). Several convection patterns which do not interact with a production region for several hours are present in this area, which allows the plasma density decay to a low value.

The trough shape is narrow in latitudes but extended in longitudes. It is typical that poleward edge is a steep wall with sudden increase of electron density, and that the amplitude even increases during the higher geomagnetic activity. The equatorial edge is flatter and it reaches the normal night-time $\mathrm{F}$ layer electron density level at lower latitudes in a less steep manner (Muldrew 1965, Werner and Prölss 1997). Position of MIT poleward edge is considered to be connected with the magnetospheric plasmapause. Yizengaw et al. (2005) have shown that the two features lie on the same field lines during geomagnetically quiet time period, which became an important step in modeling the plasmapause position at ionospheric heights. However, the correlation disappears during strong geomagnetic disturbances and plasmapause occurs inside the trough wall (Rothkaehl et al. 1997). MIT is also connected with an auroral oval, because the research of this structure indirectly gives us information about the polar region physics as well as the dynamics.

Many studies show that MIT mostly occurs during the night-time and its intensity is changing together with the distance from local midnight (Moffett and Quegan 1983). The mid-latitude trough is a very dynamic structure which is highly-reactive to changes in geomagnetic conditions. Studies have shown that the structure moves to the lower latitudes and becomes shallower with increasing level of geomagnetic activity (Moffett and Quegan 1983). Some changes in MIT location for different longitudes were also observed. Even though the dependence of the main ionospheric structures has been detected, its direct source is still not well known.

In this paper we study the general characteristics of the trough structure during the last long solar minimum. This solar cycle decline, and in particular minimum phase, seems to be unusual and that appears to be related to 
weak solar polar magnetic fields. Thus, studies of the behavior of the main ionospheric trough during this period are important for good understanding of ionospheric response to specific solar conditions. The analysis was made in respect to the season and level of the geomagnetic activity. The data from two different missions were compared.

\section{DATA COLLECTION}

In order to analyze the characteristic behavior and features of the main ionospheric trough, data received from two missions were used, namely DEMETER satellite and FORMOSAT-3/COSMIC constellation. DEMETER was a micro-satellite operating from June 2004 to 2010, located at circular orbit with inclination of $98.3^{\circ}$. Originally orbiting at an altitude of $710 \mathrm{~km}$, it lowered to $660 \mathrm{~km}$ in 2005 . One of the instruments present onboard DEMETER was Langmuir probe which provides measurements of electron density and temperature (Lebreton et al. 2006). Due to limited time of the instrument operation per orbit, the data from mission reach only $\pm 65^{\circ}$ of geomagnetic latitude. Because of the night-time character of MIT, data from night orbits were chosen and divided into two groups, depending on $K_{p}$ index value. The first group, with index between 0 and 2, was considered as a low geomagnetic activity, while the second one, with values in the range of 4-6, as a high geomagnetic activity (e.g., magnetic storm).

FORMOSAT-3/COSMIC is a joint U.S.-Taiwanese project consisting of six micro-satellites using radio occultation method to obtain information about meteorological conditions in the Earth's atmosphere. The mission was successfully launched into a circular low-Earth orbit on 15 April 2006. The initial altitude of micro-satellites was $512 \mathrm{~km}$ and it was gradually rising to the final altitude of about $800 \mathrm{~km}$, an orbit plane inclination angle of $72^{\circ}$ and a separation angle between neighboring orbit planes of $24^{\circ}$ in longitude. This RO method uses signal of operating GPS satellites to determine, e.g., atmospheric profiles, vertical water vapor content over the whole Earth. Specific character of this method provides measurements in multiple points. From one day of observation, even 2500 atmospheric profiles can be calculated. It allows us to get 3-dimensional information about atmospheric conditions.

The data from FORMOSAT-3/COSMIC's were selected at an altitude of $650 \mathrm{~km}$ to make them comparable with those from DEMETER satellite. Also time range was chosen so that it covers local night-time. Both data sets are presented in geomagnetic dipole coordinate system. To distinguish from different geomagnetic conditions that cause varied ionospheric behavior, data also were divided into two groups, basing on value of $\mathrm{Kp}$ index $(K p=(0,2)$ and $K p=(4,6))$. For both datasets seasonal maps were created in 
order to observe and analyze typical behavior of trough structure depending on solar flux condition and geomagnetic activity.

\section{SEASONAL CHANGES OF MAIN IONOSPHERIC TROUGH POSITION}

The main ionospheric trough is a phenomenon strongly correlated with solar flux and geomagnetic activity conditions. Studies show that its location and

\section{Electron density maps from DEMETER data \\ $\mathrm{Kp}$ index $=0-2$, year 2005}

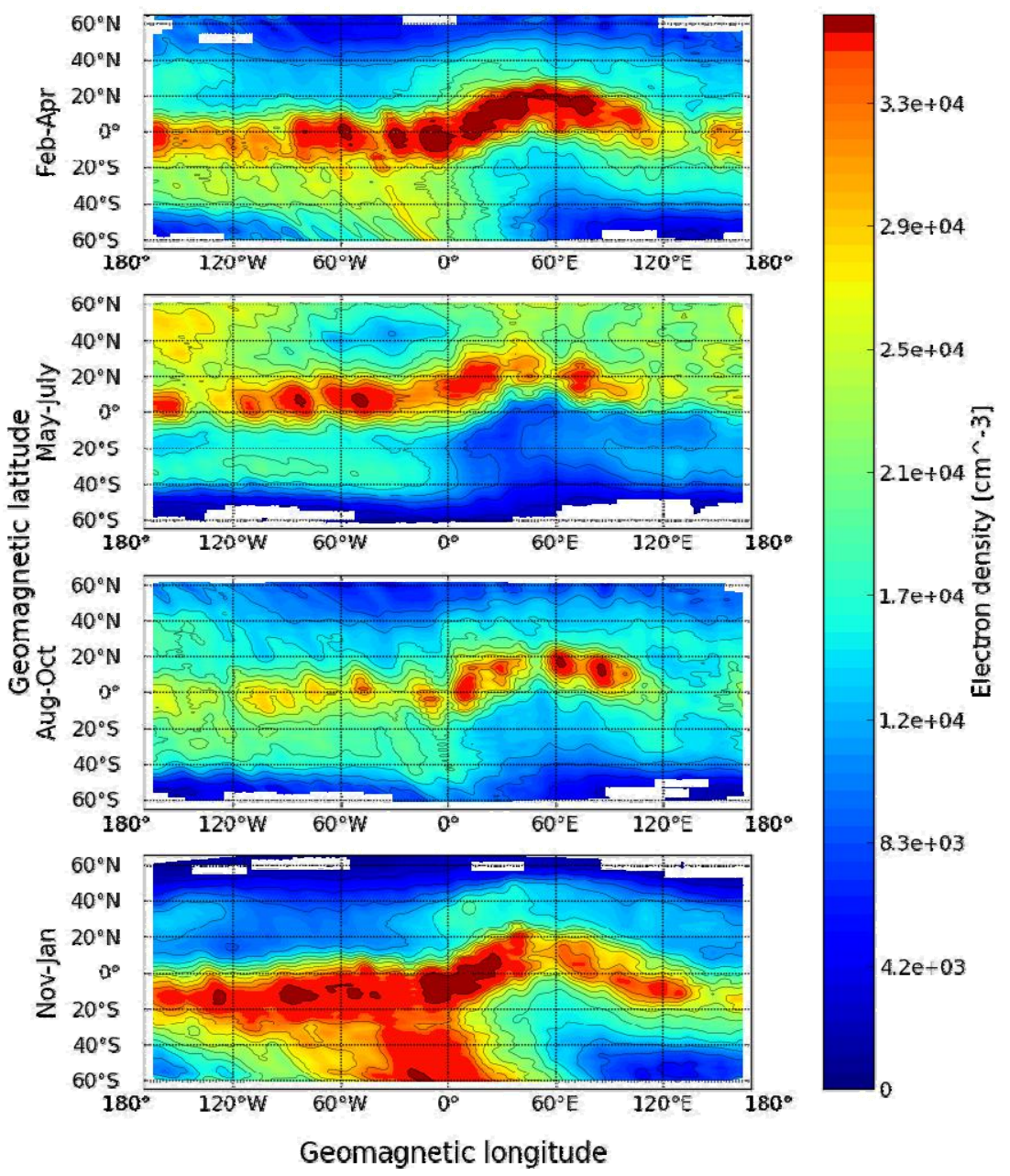

Fig. 1. Maps of seasonal changes in electron density derived from DEMETER data for $\mathrm{K}_{\mathrm{p}}$ index in the range of 0-2 in 2005 . 
shape change during different seasons. The data from DEMETER mission were selected to find typical insolation-correlated behavior of MIT on both hemispheres. The measurements for night-time orbits from Langmuir probe instrument were picked and divided into four time periods (representing the four seasons), i.e., February-April, May-July, August-October, and November-January. Data points were gridded over almost whole range of geomagnetic longitude and for geomagnetic latitudes from $-65^{\circ}$ to $65^{\circ}$. Similar

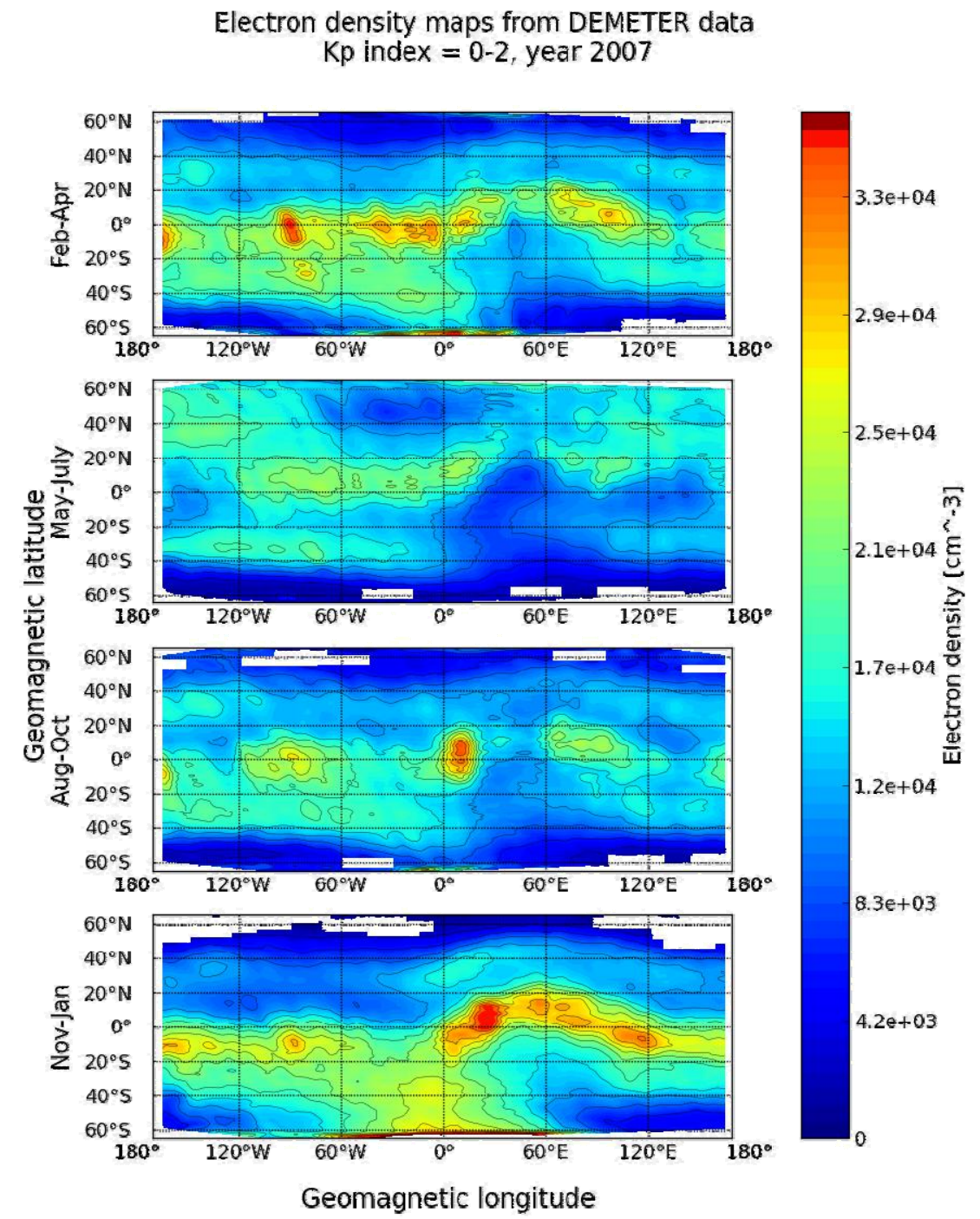

Fig. 2. Maps of seasonal changes in electron density derived from DEMETER data for $\mathrm{K}_{\mathrm{p}}$ index in the range of 0-2 in 2007. 

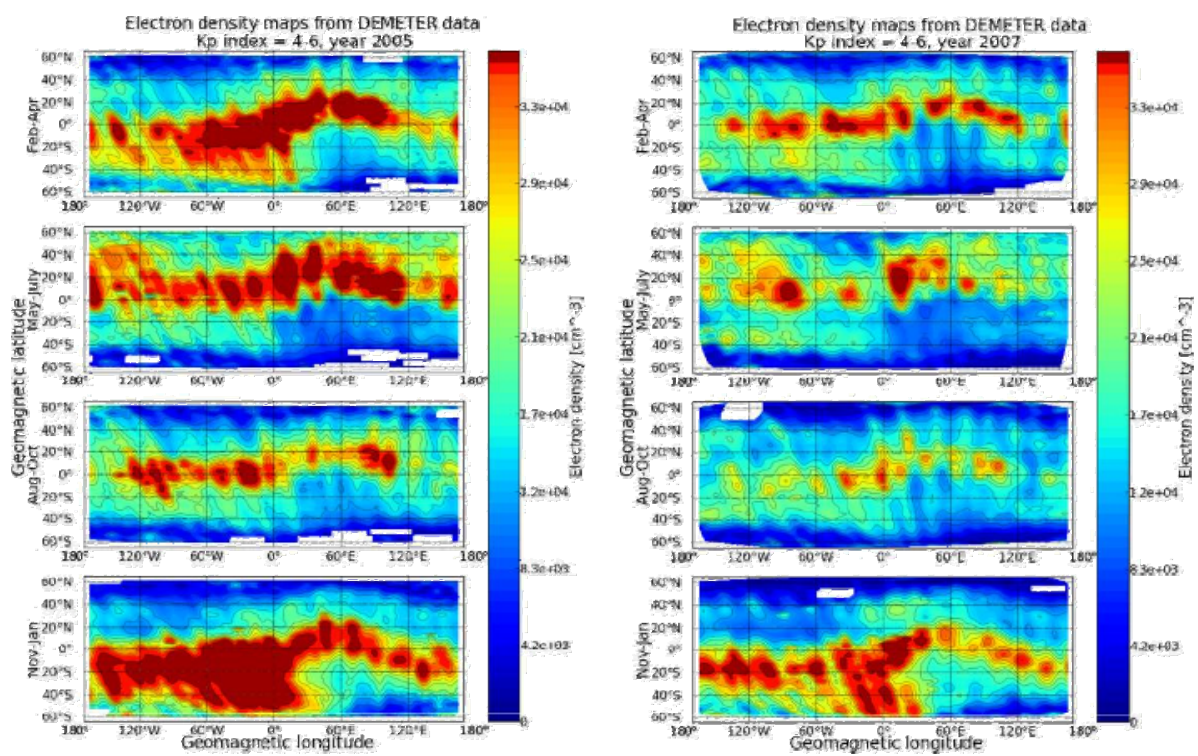

Fig. 3. Maps of seasonal changes in electron density derived from DEMETER data for $\mathrm{K}_{\mathrm{p}}$ index in the ranges of 4-6 in 2005 (left figures) and 2007 (right figures).

processing was applied for FORMOSAT-3/COSMIC data but the range available for geomagnetic latitude was higher. This allowed better analysis of the trough and its adjacent region. Also, to compare with DEMETER night-time data (local time 10:20 PM) only profiles in time range from 9:00 PM to 3:00 AM were chosen.

We can observe that the trough structure is most visible during the local winter on both hemispheres. It happens because of the shorter time when the ionosphere is sunlit. As mentioned before, the limits of DEMETER data result in the fact that only the equatorial edge of the trough and part of inner structure can be observed (blue edges of the map Figs. 1 and 2). The data show that there are regions where MIT exists almost all year long and where it is most visible under favorable conditions. For the northern hemisphere the trough can be easily observed during winter solstice months, i.e., from November till January, both on maps from DEMETER (bottom panel Figs. 1 and 2) and FORMOSAT-3 data (bottom left panel Fig. 4). It covers almost whole range of geomagnetic longitudes and the equatorial edge is located at about $50^{\circ}-55^{\circ}$ of geomagnetic latitude. On the contrary, during the same period of time, the structure on the southern hemisphere is hardly visible, and for some longitudes only. We can find weak trough for geomagnetic longitudes from $80^{\circ} \mathrm{E}$ to $160^{\circ} \mathrm{W}$ at typical latitudinal location, i.e. about $-62^{\circ}$. 

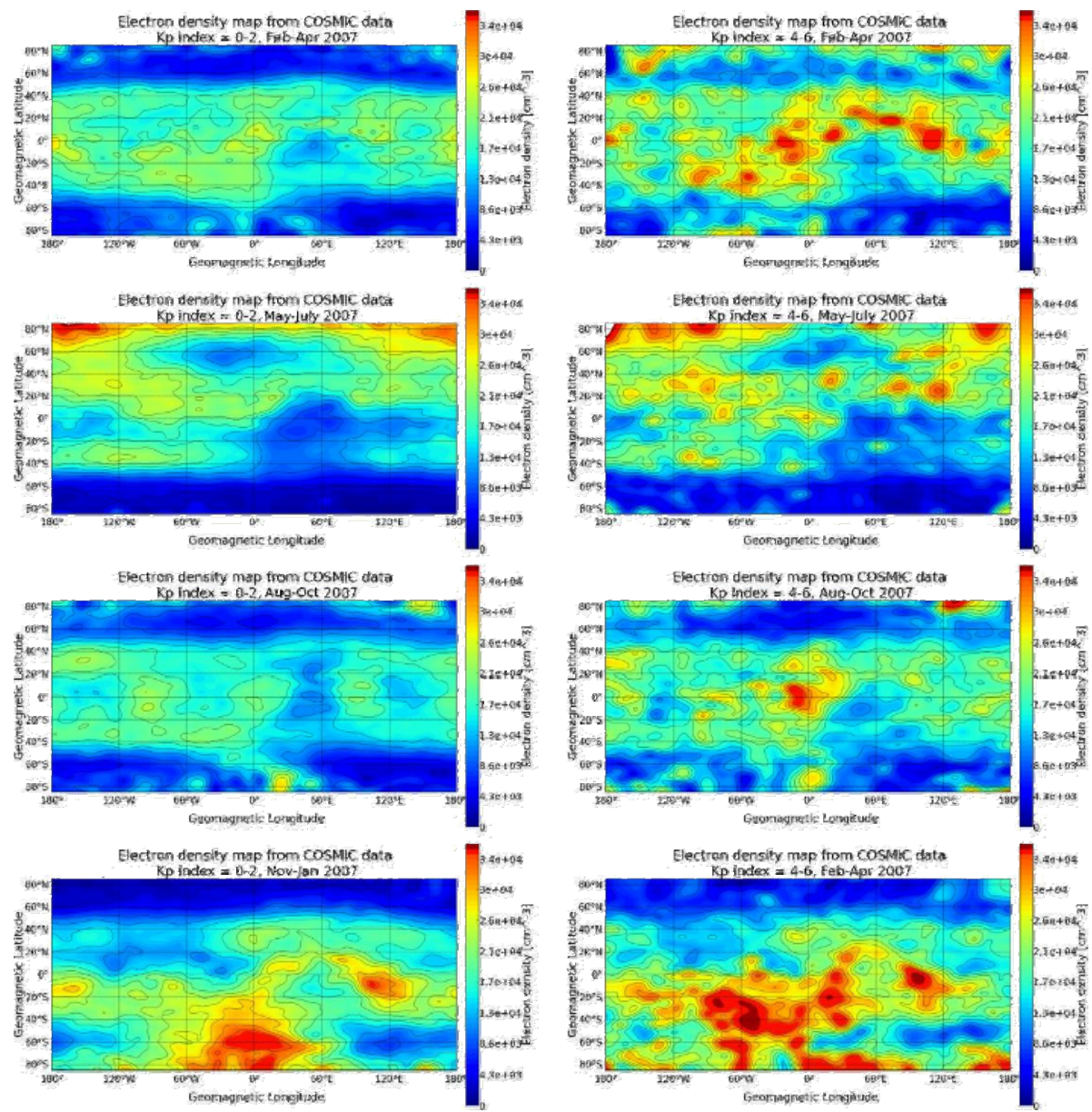

Fig. 4. Maps of seasonal changes in electron density derived from FORMOSAT3/COSMIC data for $\mathrm{K}_{\mathrm{p}}$ index in the ranges of 0-2 (left figures) and 4-6 (right figures) in 2007. Data selected for $650 \mathrm{~km}$ altitude.

When comparing troughs on the southern and the northern hemisphere we find out that during equinoxes and even local summer the trough on the southern hemisphere appears to be deeper and more visible locally than northern trough in similar solar flux conditions (Fig. 2 and left panel of Fig. 4). It could underpin the conjecture that mechanisms and physics responsible for MIT formation and behavior on the southern and northern hemispheres are quite different. In addition, the presence of Weddel Sea Anomaly on the southern hemisphere may have a significant impact on the appearance of the MIT. The night-time trough is more developed over the region of Eastern Indian Ocean because of the higher ionization available 

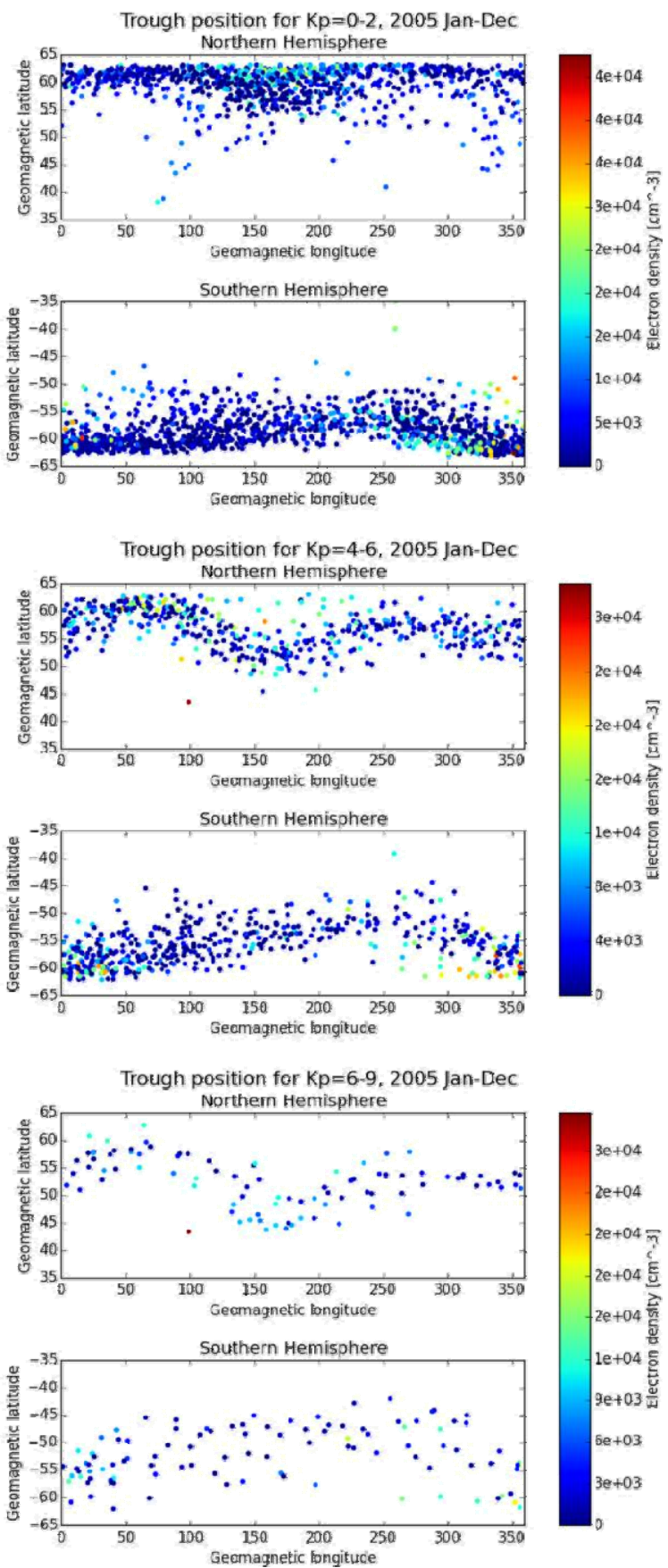

Fig. 5. Trough minimum position derived from DEMETER data for $\mathrm{K}_{\mathrm{p}}$ index in the ranges of 0-2 (top figure), 4-6 (middle figure), and 6-9 (bottom) in 2005. 
Trough position for $\mathrm{Kp}=0-2,2007$ Jan-Dec
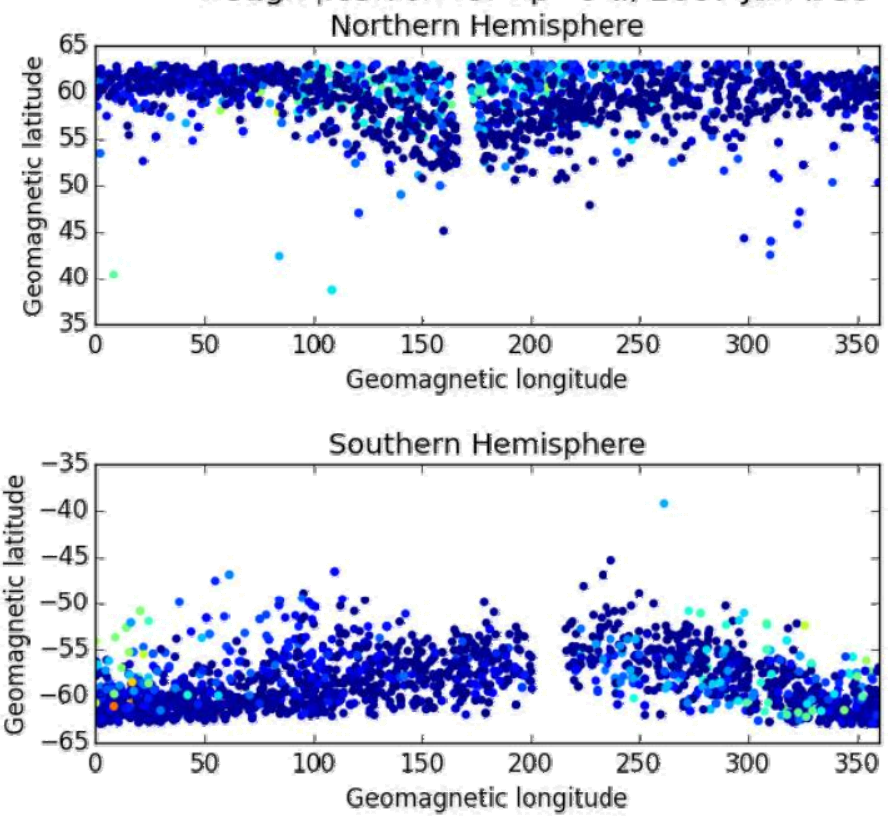

Trough position for $\mathrm{Kp}=4-6,2007$ Jan-Dec
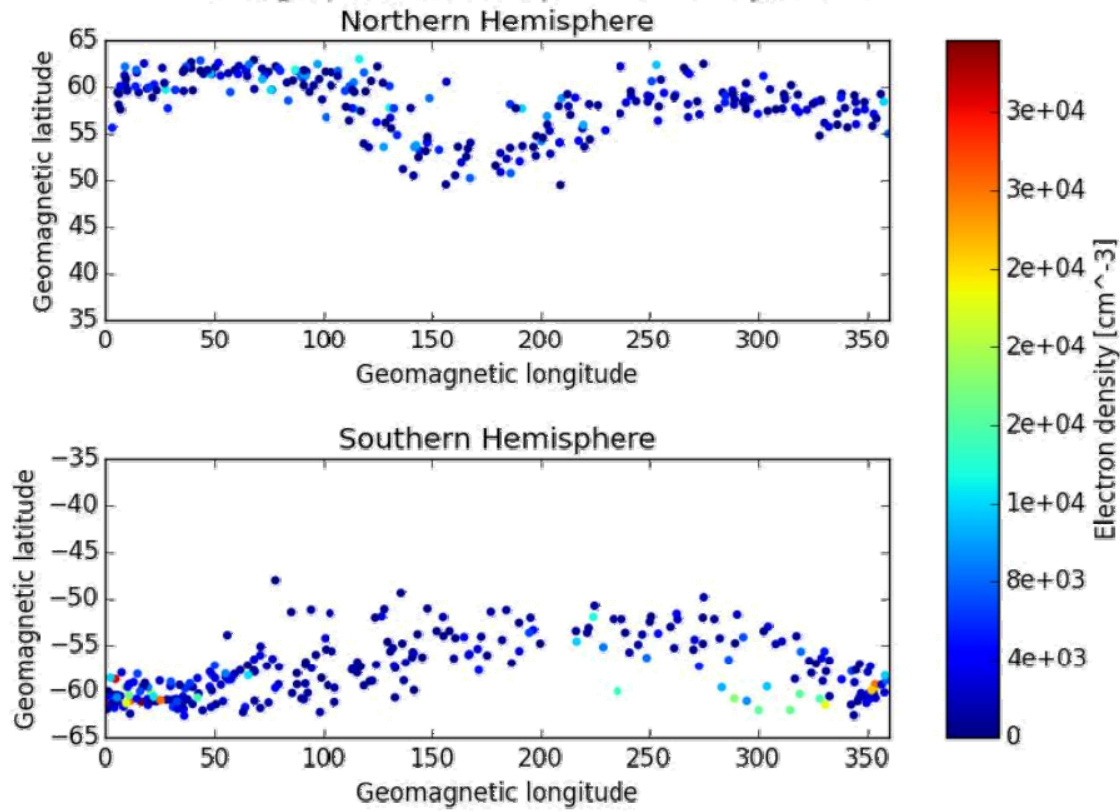

Fig. 6. Trough minimum position derived from DEMETER data for $\mathrm{K}_{\mathrm{p}}$ index in the ranges of 0-2 (top figure) and 4-6 (bottom figure) in 2007. 
(due to Weddell Sea Anomaly) than over the Mid Indian Ocean where the electron density level is lower (Horvath and Essex 2011).

In terms of geomagnetic conditions, one of the features observed is that the higher electron densities come with the higher $\mathrm{K}_{\mathrm{p}}$ index. This can be easily explained by higher particle precipitation and the trough bottom filled by electrons, through expansion of auroral oval region. We can also find greater amplitude between regions with high and low electron density (Fig. 3 and right panels of Fig. 4). Another important thing is that general annual geomagnetic conditions affect MIT characteristics as can be observed when we compare the maps created from 2005 and 2007 year. For DEMETER data from 2007, which is considered as relatively quiet period, global electron densities are lower than for data from 2005 and for the same $K_{p}$ index range (compare Figs. 1, 2, and 3). During 2005 we have experienced high solar activity with numerous strong solar flares and coronal mass ejection events, thus the Earth magnetic field was often disturbed. It resulted in general higher geomagnetic activity and enhanced energetic particles precipitation and accumulation during the disturbed periods.

The comparison between data from DEMETER and FORMOSAT-3 shows good agreement of global structures. As a result, we can consider the behavior of mid-latitude trough presented here as typical for seasonal changes.

\section{TROUGH MINIMUM POSITION}

The typical location for MIT structure during the solar activity maximum is estimated to be about $60^{\circ}-65^{\circ}$ of geomagnetic latitude. Simple analysis was made in order to find the main trough location for time period corresponding to solar activity minimum. From DEMETER data, night-time orbits have been selected and ranges corresponding to the main ionospheric trough location have been picked (i.e., $35^{\circ}$ to $65^{\circ}$ geomagnetic latitude). The region where density minimum was clearly visible and which was correlated with electron temperature maximum was considered as trough minimum. Orbits were divided into three groups, for low, moderate and high geomagnetic activity. Kp index in the ranges: 0-2, 4-6, and 6-9 has been chosen as an indicator of geomagnetic activity. In Fig. 5 plots for the trough minimum position in 2005 for different geomagnetic conditions are shown. From the quiet period we can find that the trough minimum locates at about $60^{\circ}-63^{\circ}$, which is consistent with literature. Geomagnetic disturbances cause shift of the minimum trough location as expected (Muldrew 1965) and for moderate conditions it is placed at about $55^{\circ}-60^{\circ}$ (middle panel). There were several extremely strong geomagnetic events in 2005 ; thus, it was possible to make some statistics in case when $\mathrm{K}_{\mathrm{p}}$ index exceeded the value of 6 . Bottom panel 

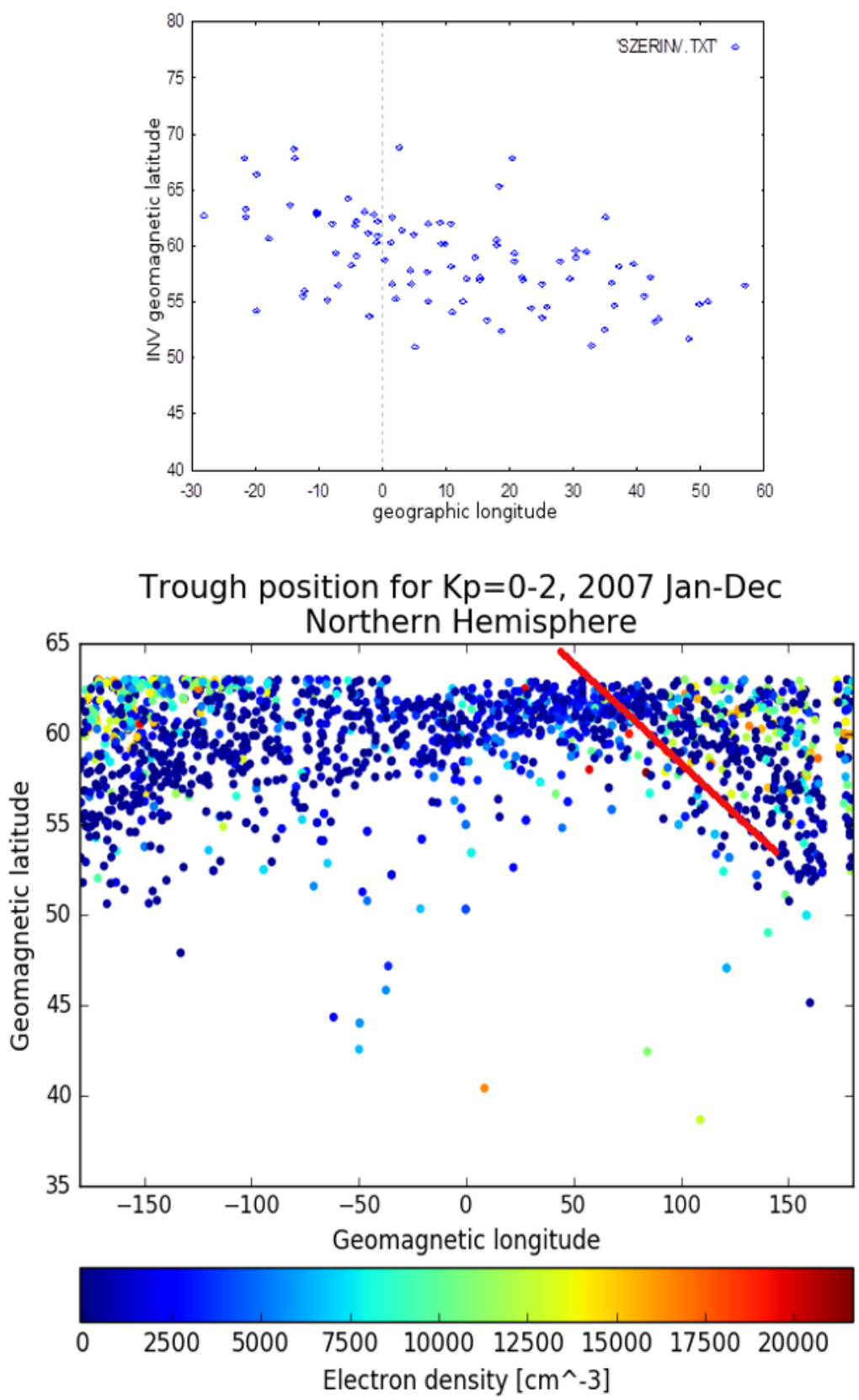

Fig. 7. Trough minimum position derived from radio measurements in the topside ionosphere from Magion-3 spacecraft (top) and from DEMETER data for $\mathrm{K}_{\mathrm{p}}$ index in the range of $0-3$ in 2005 (bottom). Red line corresponds to the position of Magion-3 measurements. 
shows that for high geomagnetic activity the MIT minimum moves equatorward and can reach even $47^{\circ}-50^{\circ}$ of geomagnetic latitude. Figure 6 represents the estimated trough minimum positions for year 2007. Only two plots were made for low and moderate activity, as in 2007 extremely strong events were rarer. We find similar position for low $K_{p}$ as in 2005 . For the range 4-6, the trough minimum moves few degrees towards equator.

Analyzing the MIT minimum we can observe that its location differs with longitudes. There are regions where the structure estimated minimum is shifted to the lower latitudes. This situation takes place for longitudes in sector from $100^{\circ}$ to $160^{\circ}$ for the northern hemisphere. Similar behavior can be found for the southern hemisphere trough. Position of the minimum moves to the lower latitudes between $170^{\circ}$ and $300^{\circ}$ of geomagnetic longitude. Analyzing Fig. 7 we can find out that the trough position shift for this longitude sector is not an accidental feature, but rather a characteristic attribute since it can be found in measurements from different missions. For example, the trough minimum location displacement has been observed by Magion-3, operating between 18 December 1991 and December 1992 during the maximum solar activity. In contrary, the measurements conducted by DEMETER fall into the minimum solar activity. This leads to the hypothesis that the MIT longitudinal dependence may be associated with the Earth's local conditions such as neutral winds or particle flow rather than only with the geomagnetic conditions imposed by the Sun. However, further studies are needed.

\section{CONCLUSIONS}

The data from two space missions, DEMETER and FORMOSAT3/COSMIC, were used to analyze the behavior of the mid-latitude trough structure during the solar minimum period. Annual variations of the shape, location and intensity of the phenomenon were examined by means of electron density at specified altitude, latitude and longitude. It was shown that longitudinal variations of position of mid-latitude trough are strongly correlated with seasonal changes and insolation. Local winter is for both hemispheres the period when the structure appears to be the deepest and well developed, while during local summer it becomes hardly visible and much weaker. However, the southern hemisphere trough structure appears as deeper and better visible even during the local summer.

What plays an important role in MIT characteristic changes are also the Earth's magnetic field disturbances and particle precipitation. It has been shown that the typical latitudinal location of mid-latitude trough minimum is about $\pm 62^{\circ}$, but during the higher geomagnetic activity it moves equatorward even up to $5^{\circ}$. We can assume this to be a characteristic behavior since the 
data analysis from 2005 and 2007 year have shown some consistent results. Observations show also that the MIT tends to shift equatorward for some longitudes in both hemispheres. The mid-latitude trough is a dynamic structure sensitive to magnetic and particle disturbances. To better understand the complexity of its behavior, several further studies are needed.

Acknowledgements This work was conducted in the frame of the Polish-Taiwanese Joint Research Project for years 2012-2014 under the agreement between the Polish Academy of Sciences in Warsaw, Poland, and the National Science Council in Taipei, Taiwan. The work was partially funded by RELEC grant no. NCN 2012/07//04414. We acknowledge the University Corporation for Atmospheric Research (UCAR) for providing the COSMIC Data. We would like to thank the DEMETER Team for preparing the data. Additionally, we would like to thank M. Parrot, CNRS/LPCE Laboratory in Orleans, France and CDPP team for making the data available.

\section{References}

Aladjev, G.A., O.V. Evstaev, V.S. Mingalev, G.I. Mingaleva, E.D. Tereshchenko, and B.Z. Khudukon (2001), Interpretation of ionospheric F-region structures in the vicinity of ionization trough observed by satellite radio tomography, Ann. Geophys. 19, 1, 25-36.

Clilverd, M.A., N.R. Thomson, and A.J. Smith (1995), The effect of the mid-latitude ionospheric trough on whistler mode ducting during magnetic storm, $J$. Atmos. Terr. Phys. 57, 8, 945-954, DOI: 10.1016/0021-9169(94)00083-Z.

He, M., L. Liu, W. Wan, and B. Zhao (2011), A study on the night-time midlatitude ionospheric trough, J. Geophys. Res. 116, A5, A05315, DOI: 10.1029/ 2010JA016252.

Horvath, I., and E.A. Essex (2003), The Weddell Sea Anomaly observed with the Topex satellite data, J. Atmos. Sol. Terr. Phys. 65, 6, 693-706, DOI: 10.1016/S1364-6826(03)00083-X.

Karpachev, A.T. (2003), The dependence of the main ionospheric trough shape on longitude, altitude, season, local time, and solar and magnetic activity, Geomagn. Aeron. 43, 2, 239-251.

Lebreton, J.-P., S. Stverak, P. Travnicek, M. Maksimovic, D. Klinge, S. Merikallio, D. Lagoutte, B. Poirier, P.-L. Blelly, Z. Kozacek, and M. Salaquarda (2006), The ISL Langmuir probe experiment processing onboard DEMETER: Scientific objectives, description and first results, Planet. Space Sci. 54, 5, 472-486, DOI: 10.1016/j.pss.2005.10.017. 
Mallis, M., and E. Essex (1993), Diurnal and seasonal variability of the southernhemisphere main ionospheric trough from differentialphase measurements, J. Atmos. Terr. Phys. 55, 7, 1021-1037, DOI: 10.1016/0021-9169(93) 90095-G.

Moffett, R.J., and S. Quegan (1983), The midlatitude trough in the electron concentration of the ionospheric Flayer: A review of observations and modeling, $J$. Atmos. Terr. Phys. 45, 5, 315-343, DOI: 10.1016/S0021-9169(83)80038-5.

Muldrew, D.B. (1965), Flayer ionization trough deduced from Alouette data, J. Geophys. Res. 70, 11, 2635-2650, DOI: 10.1029/JZ070i011p02635.

Rothkaehl, H., F. Jiricek, J. Smilauer, and M. Förster (1997), Dynamic changes in the outer ionosphere in the region of the ionospheric trough during and intense magnetic storm, Adv. Space Res. 20, 3, 409-414, DOI: 10.1016/ S0273-1177(97)00701-1.

Spiro, R.W. (1978), Ion convection and the formation of the midlatitude F region ionization trough, J. Geophys. Res. 83, A9, 4255-4264, DOI: 10.1029/ JA083iA09p04255.

Werner, S., and G.W. Prölss (1997), The position of the ionospheric trough as a function of local time and magnetic activity, Adv. Space Res. 20, 9, 17171722, DOI: 10.1016/S0273-1177(97)00578-4.

Whalen, J.A. (1989), The daytime F layer trough and its relation to ionosphericmagnetospheric convection, J. Geophys. Res. 94, A12, 17169-17184, DOI: 10.1029/JA094iA12p17169.

Yizengaw, E., H. Wei, M.B. Moldwin, D. Galvan, L. Mandrake, A. Mannucci, and X. Pi (2005), The correlation between mid-latitude trough and the plasmapause, Geophys. Res. Lett. 32, 10, L10102, DOI: 10.1029/2005GL022954.

Zaalov, N.Y., H. Rothkaehl, A.J. Stocker, and E.M. Warrington (2013), Comparison between HF propagation and DEMETER satellite measurements within the mid-latitude trough, Adv. Space Res. 52, 5, 781-790, DOI: 10.1016/j.asr. 2013.05.023.

Received 15 September 2015

Received in revised form 29 March 2016

Accepted 26 July 2016 